\title{
Computed Tomographic Findings in the Nasal and Paranasal Sinuses of Patients Scheduled for Rhinoplasty at Mostafa Khomeini Hospital between 2011-13
}

\author{
Mehdi Abbasi ${ }^{1}$, Mohammad Ebrahim Yarmohammadi², Poopak Izadi ${ }^{2}$ \\ 1 Shahed University School of Medicine, Tehran, Iran \\ 2 Department of Otorhinolaryngology, Shahed University School of Medicine, Tehran, Iran \\ Mehdi Abbasi, ORCID:0000-0001-6978-2563 \\ Mohammad Ebrahim Yarmohammadi, ORCID:0000-0001-8520-75262 \\ Poopak Izadi, ORCID:0000-0001-9683-9959
}

\begin{abstract}
Objective: Rhinoplasty is done to improve the morphology of the nose whilst also restoring its physiological function. Currently it is possible to perform rhinoplasty and endoscopic sinus surgery simultaneously. The need has therefore arisen to evaluate anatomical variation within the nose and paranasal sinuses in symptom-free patients who are scheduled for rhinoplasty. Coronal computed tomography (CT) is the standard method used to evaluate the nose and paranasal sinuses. We aimed to evaluate the frequency of anatomical variation noted within the nose and paranasal sinuses on coronal CT in patients scheduled for rhinoplasty.
\end{abstract}

Methods: This is a descriptive, cross-sectional, retrospective study of CT findings in 84 patients who underwent rhinoplasty at Mostafa Khomeini Hospital, Shahed University, Tehran between 2011-13. The CT findings were evaluated in three different predefined categories: nasal septal, nasal turbinate, and paranasal sinuses abnormalities.

Results: The study involved 84 individuals, consisting of 26 men and 58 women. The most frequent findings in the nasal septum category were nasal septal deviation $(69.04 \%)$ and nasal septal spur (33.33\%), whereas concha bullosa $(45.23 \%)$ and inferior turbinate hypertrophy were the most frequent abnormality in the nasal turbinates category. Mucosal thickening of the sinuses $(45.23 \%)$ and partial opacification of the sinuses $(21.42 \%)$ were the most common findings in the paranasal sinuses.

Conclusion: The high frequency of anatomical variation, inflammatory and congenital abnormal findings in CT images of the paranasal sinuses in patients scheduled for rhinoplasty indicates that preoperative $\mathrm{CT}$ examination may be useful in avoiding multiple surgical operations and in reducing costs.

Keywords: Rhinoplasty, computed tomography, nasal septum, nasal concha, paranasal sinuses.
Correspondence: Poopak Izadi

Otolaryngology Department, Shahid Mostafa Khomeini Hospital, Italia Ave., Keshavarz Blvd., Tehran, Iran

E mail: popakizadi@yahoo.com

Received: 13.11.2019; Accepted: 2.12.2019
Online available at: www.entupdatesjournal.org 


\section{Introduction}

Rhinoplasty is a surgical procedure which modifies the appearance and function of the nose by alteration of the nasal skin, cartilages, and bones. It is either corrective or cosmetic. Corrective rhinoplasty is performed in cases of nasal tumour, congenital defect, trauma or surgical injury. The aim of cosmetic rhinoplasty is to enhance the appearance of the nose while maintaining nasal function. ${ }^{[1]}$ Nasal cosmetic surgery is one of the most common and yet interesting and challenging types of cosmetic procedure. The final result of the operation cannot be predicted with certainty since the dynamicity of the nasal tissues can influence the outcome. In addition, there are both normal and abnormal variations within the nasal and paranasal sinus structures that can affect the final results. ${ }^{[2]}$

Given that the majority of patients seeking rhinoplasty have nasal obstruction or sinus problems, such as inflammatory disorders, anatomical deformity, or osteomeatal complex obstruction and that simultaneous rhinoplasty and functional endoscopic sinus surgery (FESS) has become feasible, careful evaluation of such problems prior to surgery is clearly crucial. ${ }^{[3,4]}$ Computed tomography (CT) is the method of choice and the most reliable modality for evaluating the extent of sinonasal disease and displaying the bony and soft tissues and anatomical variations as well as congenital and inflammatory problems of the nose and paranasal sinuses. ${ }^{[5-7]}$ The aim of the present study was to evaluate the CT findings in three different areas, i.e. nasal septum, nasal turbinates, and paranasal sinuses, in patients scheduled for rhinoplasty. By identifying anatomical variations and pathological problems, more suitable preoperative surgical plans can be drawn up, which can save time and money as well as prevent multiple operations and related complications.

\section{Materials and Methods}

This was a descriptive, cross-sectional, retrospective study of CT findings in 84 patients who underwent rhinoplasty at Mostafa Khomeini Hospital, Shahed University, Tehran during 2011-13. Patients with a previous history of rhinoplasty, septoplasty or FESS, as well as those with acute sinusitis, were excluded from the study.

The CT findings on the patients were gathered and entered into a specially designed data collection form. The patients were informed about the aims and protocol of the study and informed consent was obtained verbally from them. The data were sorted into three separate cate- gories: nasal septum (spur, tubercle, deviation, etc.); nasal turbinate (concha bullosa, hypertrophy, paradoxical middle turbinate, etc.) and paranasal sinus disorders (total or partial opacification, mucosal thickening, cyst retention, etc.). All CT examinations were performed in coronal section with $3-\mathrm{mm}$ cuts using a Shimadzu Model 8500 scanner (Shimadzu Corporation, Kyoto, Japan). The data from the patients' archived files as well as the CT findings were assembled, then analysed using the Statistical Package for the Social Sciences application (v. 18; SPSS Inc., Chicago, IL, USA). Descriptive statistics were reported.

\section{Results}

The age range of the 84 cases scheduled for rhinoplasty was $19-44$ years (mean=25.3 years), of which, $58(68.29 \%)$ were female and $26(31.71 \%)$ male. Amongst nasal septal disorders, deviation was the most common (58 patients, 69.04\%), whereas concha bullosa was the most common pathology to affect the nasal turbinates (38 patients, $45.23 \%$ ) (Table 1). Increased mucosal thickening was the most prevalent pathology involving the paranasal sinuses. Increased mucosal thickening was most common at ages 25-29 years. There was no correlation with the sex of the patient. The other paranasal sinus findings, including anatomical variations, are presented in Tables 2 and 3.

\section{Discussion}

Many patients with cosmetic nasal concerns also have functional complaints such as sinus problems and/or nasal septum or turbinate abnormalities. The surgeon operating on the nose needs to have the full picture about these functional problems before surgery commences. In addition, many patients with sinonasal complaints also seek cosmetic improvement. Clear and complete information about the sinonasal anatomy and its variants in individual cases allows for a better surgical approach. Preoperative paranasal sinus CT scanning is the modality of choice for diagnosis and assessment of the nasal cavity and paranasal sinuses. In this study, we assessed paranasal sinus CT scans of patients who went on to have rhinoplasty.

Evaluating the nasal septum constitutes a major part of the assessment of the nose and paranasal sinuses. Paranasal sinus CT scanning is very accurate in the evaluation of the nasal septum prior to septorhinoplasty. ${ }^{\left[{ }^{[8]}\right.}$ Addressing any issues with the septal cartilage is a key task, since the septum is the most important source of grafts used in rhinoplasty. According to Bolger's theory, non-traumatic nasal 


\begin{tabular}{lcccc}
\hline \multicolumn{4}{l}{ Table 1. Computed tomographic findings of nasal septum and turbinates in patients underwent rhinoplasty. } \\
\hline Nasal septum and turbinate pathologies & Right (n) & Left (n) & Bilateral (n) & Total (n) \\
\cline { 2 - 5 } Septal deviations & $28(33.33 \%)$ & $30(35.71 \%)$ & - & $58(69.04 \%)$ \\
Septal spur & $10(11.9 \%)$ & $18(21.42 \%)$ & - & $28(33.33 \%)$ \\
Concha bullosa & $14(16.66 \%)$ & $6(7.14 \%)$ & $18(21.42 \%)$ & $38(45.23 \%)$ \\
Inferior turbinate hypertrophy & - & $4(4.76 \%)$ & $8(9.52 \%)$ & $12(14.28 \%)$ \\
Paradoxical middle turbinate & - & - & $10(11.9 \%)$ & $10(11.9 \%)$ \\
\hline
\end{tabular}

\begin{tabular}{|c|c|c|c|c|c|c|}
\hline Paranasal sinus & Side & $\begin{array}{l}\text { Increased mucosal } \\
\text { thickening }(n)\end{array}$ & $\begin{array}{l}\text { Partial Opacifica- } \\
\text { tion (n) }\end{array}$ & $\begin{array}{c}\text { Total Opacification } \\
\text { (n) }\end{array}$ & $\begin{array}{l}\text { Retention cyst } \\
\text { (n) }\end{array}$ & $\begin{array}{l}\text { Osteomeatal } \\
\text { obstruction (n) }\end{array}$ \\
\hline \multirow{3}{*}{ Ethmoid sinus } & Right & $2(2.38 \%)$ & - & - & - & - \\
\hline & Left & $2(2.38 \%)$ & - & - & - & - \\
\hline & Bilateral & $8(9.52 \%)$ & - & - & - & - \\
\hline \multirow{3}{*}{ Frontal sinus } & Right & - & - & - & - & - \\
\hline & Left & $2(2.38 \%)$ & - & - & - & - \\
\hline & Bilateral & - & $4(4.76 \%)$ & - & - & - \\
\hline \multirow{3}{*}{ Maxillary sinus } & Right & $6(7.14 \%)$ & $4(4.76 \%)$ & - & $4(4.76 \%)$ & - \\
\hline & Left & $8(9.52 \%)$ & $4(4.76 \%)$ & - & - & $2(2.38 \%)$ \\
\hline & Bilateral & $10(11.9 \%)$ & $6(7.14 \%)$ & - & - & - \\
\hline Total & & $38(45.23 \%)$ & $18(21.42 \%)$ & & $4(4.76 \%)$ & $2(2.38 \%)$ \\
\hline
\end{tabular}

\begin{tabular}{|c|c|c|c|c|}
\hline Paranasal cells & Right (n) & Left $(n)$ & Bilateral (n) & Total (n) \\
\hline Haller cell & - & $4(4.76 \%)$ & - & $4(4.76 \%)$ \\
\hline Agger nasi cell & $2(2.38 \%)$ & $2(2.38 \%)$ & $6(7.14 \%)$ & $10(11.9 \%)$ \\
\hline Onodi cell & $2(2.38 \%)$ & $2(2.38 \%)$ & $4(4.76 \%)$ & $8(9.52 \%)$ \\
\hline Frontal cell & $4(4.76 \%)$ & $4(4.76 \%)$ & $4(4.76 \%)$ & $12(14.28 \%)$ \\
\hline
\end{tabular}

septal deviation, especially where the cartilage and vomer join, can be seen in $10 \%$ of the normal population. ${ }^{[9]}$ This prevalence has been reported as between $21 \%$ and $75 \%$ in different studies. ${ }^{[7,10-15]}$ In our study, the prevalence of a nasal spur was $33.33 \%$ and nasal septal deviation was found in $69.04 \%$ of cases. The prevalence of nasal septal deviation in our study was very similar to that found in reports from other parts of Iran. The difference in prevalence seen when compared with the reports from other countries may be attributable to racial differences, larger sample sizes, or different study populations (for example, studies including patients with sinusitis).

Concha bullosa (i.e. pneumatisation of the middle turbinate) ranges in size from very large to very small. It can 
lead to mucosal contact within the osteomeatal complex, middle meatus obstruction, ethmoiditis, maxillary sinusitis, and even mucocoele. The prevalence of concha bullosa in our study was $45.23 \%$, while it has been reported to be between $9.09 \%$ and $61 \%$ in the literature. ${ }^{[7,10-12,15,16]}$ The reason for the apparently varying prevalence is that different definitions of the concha bullosa are in use. In studies reporting a higher prevalence, any air in the middle turbinate was considered concha bullosa, whilst in our study, only air in the bullous part of the middle turbinate was counted as concha bullosa.

Another anatomical variation in middle meatus is paradoxical middle turbinate, a condition in which the middle turbinate deviates laterally. This condition can lead to stricture of the middle meatus and sinusitis, either per se or when accompanied by other anatomical variations. The prevalence of paradoxical middle turbinate in our study was $11.9 \%$, while the prevalence has been reported as $3.03 \%$ to $26.1 \%$ in other studies. ${ }^{[9,15,17-19]}$ In all the studies mentioned above the prevalence of a paradoxical middle turbinate of sufficient degree to affect the middle meatus was evaluated, whilst in our study we evaluated the prevalence of paradoxical middle turbinate, whether it could affect the middle meatus or not.

More than $20 \%$ of patients referred with nasal obstruction have turbinate hypertrophy. Inferior turbinate hypertrophy can be an important factor in nasal obstruction, especially in those patients with maxillary crest or nasal septal deviation. Severe nasal septal deviation can lead to compensatory hypertrophy of the inferior turbinate on the contralateral side. ${ }^{[20]}$ In our study the rate of inferior turbinate hypertrophy was $14.28 \%$.

Agger nasi cells are any of the anterior ethmoid cells, which are located in the anterior of the frontal recess. They normally lead to no complications. However, if they extend posteriorly, they may constrict the frontal recess, leading to frontal sinus problems. An agger nasi cell, due to its vicinity to the lacrimal sac, may lead to inflammation of the lacrimal sac, producing tearing. The prevalence of such conditions varies between studies, ranging from $2 \%$ to $80 \%$. ${ }^{17,9-}$ ${ }^{11,21,22]}$ The prevalence of such cells in our study was $11.9 \%$. The reason for such differences in reported prevalence is that in some studies only large agger nasi cells were considered, whilst in our study, in line with the work of Zinreich ${ }^{[23]}$, any air cell below the frontal sinus and bordered superiorly by the frontal recess, located laterally to the lacrimal sac, and anteriorly to the lacrimal bone was considered an agger nasi cell.

Haller cells are defined as ethmoidal air cells that may protrude into the orbital floor and narrow the maxillary ostium. The frequency of these cells has been reported as $4 \%$ to $39 \%$, in various studies. ${ }^{[7,24]}$ Significant pneumatisation within such a cell can lead to obstruction of the maxillary sinus orifice, resulting in ethmoiditis and maxillary sinusitis, but the presence of such a cell is not necessarily pathological. In our study the prevalence of Haller cells was $4.76 \%$. Our study found a prevalence in line with other studies conducted in Iran. The prevalence is low compared to other anatomical variations in the paranasal sinuses. Although there is an apparent difference in the reported prevalence in the literature, this can be explained by use of differing definitions of the Haller cell, or because of differences in the CT technique used.

The Onodi cell is the most posterior cell of the ethmoid. It is very important because of its vicinity to the carotid canal and the optic nerve. Its position should be considered during endoscopic sinus surgery. The prevalence of an Onodi cell in Talaiepour's study was 7\% ${ }^{[1]}$, in Stammberger's $8 \%{ }^{[25]}$, and in our study $9.52 \%$. The results are similar in each study.

Anterior ethmoidal air cells are referred to as frontal recess cells if they are positioned towards the frontal area. The prevalence of this type of cell has been reported as between $20 \%-41 \%$ in various studies. ${ }^{[26-28]}$ In our study, the rate of a frontal cell was $14.28 \%$. Such a difference in prevalence may be due to the fact that different populations were involved in the study. In Karzki's study ${ }^{[26]}$, patients with chronic rhinosinusitis were investigated, whilst in Han's research ${ }^{[28]}$, Chinese patients were studied. Furthermore, unlike in our study, Han's study involved axial CT as well as coronal CT to diagnose all types of frontal cells. ${ }^{[28]}$ In the study by Abdi et al ${ }^{[16]}$ involving patients referred with symptoms of chronic sinusitis, osteomeatal complex obstruction was seen in $45.6 \%$ and pansinusitis in $17.3 \%$ of the patients. In another study, a significant relationship between some anatomical variations and the extent of sinus mucosal disease has been reported following evaluation of CT scans. ${ }^{[7]}$ As these studies were done on patients with chronic sinusitis, their findings cannot be directly compared with our results. We could not identify any other study done on the prevalence of sinus diseases in individuals without sinus symptoms. 


\section{Conclusion}

We have discovered that there are anatomical variations and particular findings in the CT findings of patients scheduled for rhinoplasty. The most frequent findings were septal deviation and concha bullosa. The high frequency of anatomical variation, inflammatory and congenital abnor-mal findings in CT images of the paranasal sinuses in pa-tients scheduled for rhinoplasty indicates that preoperative CT examination may be useful in avoiding multiple surgi-cal operations and in reducing costs, as well as managing such conditions.

Acknowledgements: We wish to thank all the patients who verbally consented to use of their sinus CT results in this study. The assistance of the personnel within the CT department is also appre-ciated.

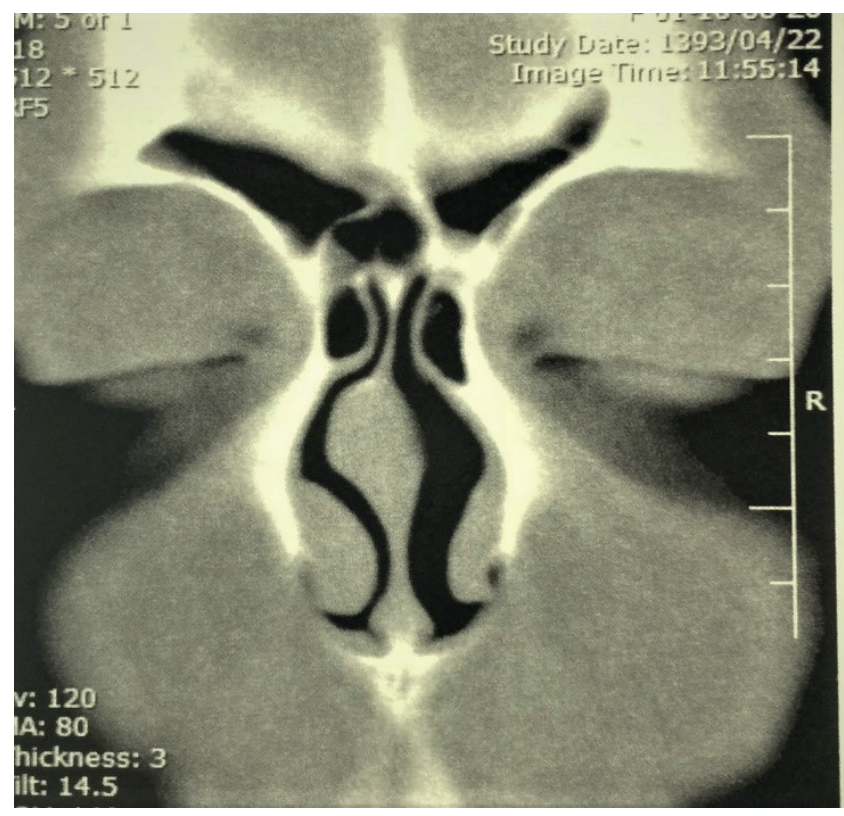

Figure 1. A coronal CT image of an agger nasi cell.
Ethics Committee Approval: This article is based on the thesis submitted by Dr Mehdi Abbasi, which was granted ethical approval in March 2014 (No. P-577/86).

Informed Consent: Informed consent was obtained from all individual participants included in the study.

Author Contributions: Designing the study - M.A., M.E.Y, P.I.; Collecting the data - M.A., M.E.Y, P.I.; Ana-lysing the data - M.A., M.E.Y, P.I.; Writing the manuscript - M.A., M.E.Y, P.I.; Confirming the accuracy of the data and the analyses - M.A., M.E.Y, P.I.

Conflict of Interest: The authors have no conflict of in-terest to declare.

Financial Disclosure: The authors declare that no finan-cial support was received for this paper.

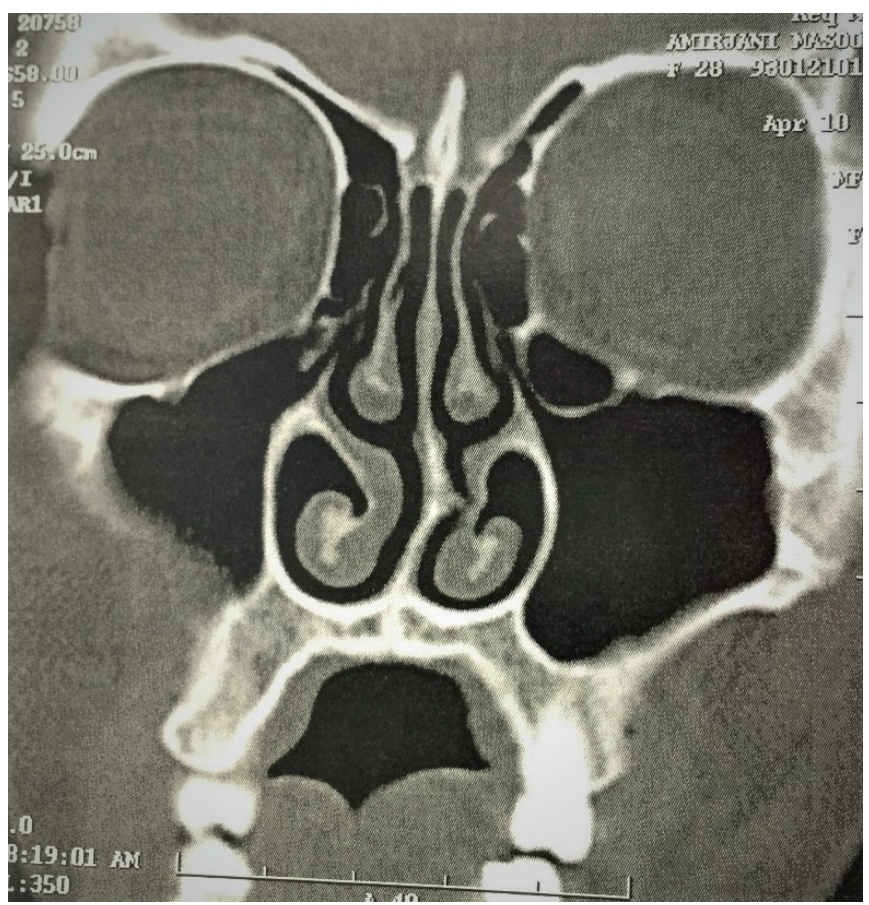

Figure 2. A coronal CT image of a Haller cell 


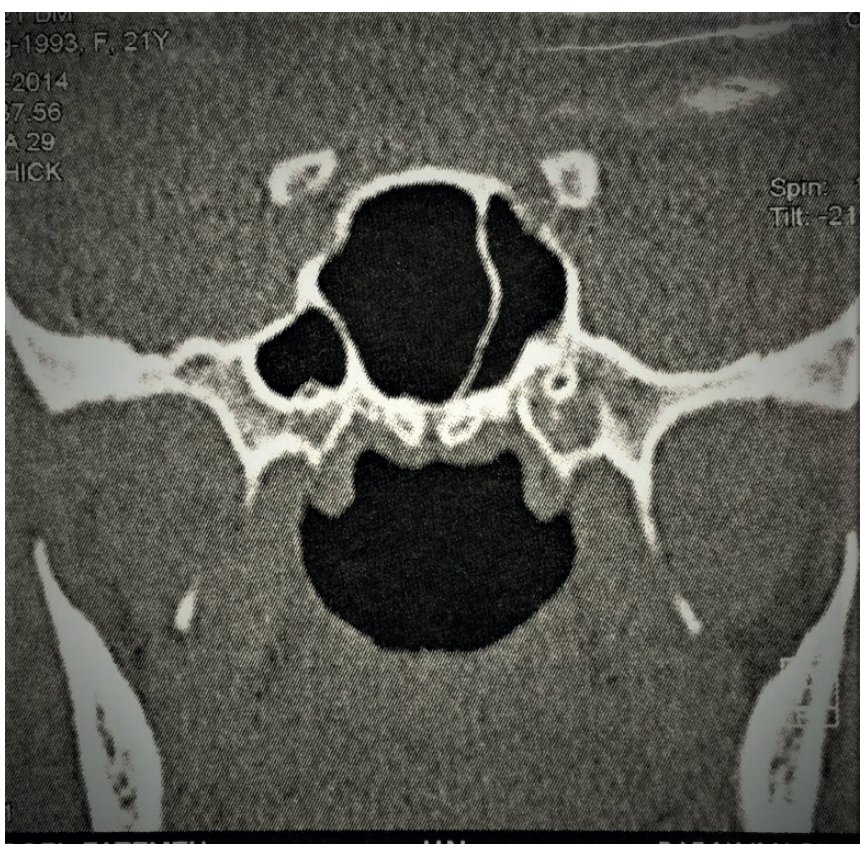

Figure 3. A coronal CT image of an Onodi cell

\section{References}

1. Hammad MS, Gomaa MA. Role of some anatomical nasal abnormalities in rhinogenic headache. Egypt J Ear Nose Throat All Sci 2012;13:31-5.

2. Hafezi F, Kouchakzadeh K, Naghibzadeh B. History and status of nose surgery. Iranian Journal of Surgery 2009;17:88-94.

3. Bradoo R. Anatomical Principles of Endoscopic Sinus Surgery: A Step by Step Approach. In: Pitman KT, editor. Book reviews. Head Neck 2007;29:302.

4. Muhammad IA, Rahman NU. Complications of the surgery for deviated nasal septum. J Coll Physicians Surg Pak 2003;13:565-8

5. Flint PW, Haughey BH, Lund VJ, et al. Cummings Otolaryngology Head and Neck Surgery. 6th ed. Philadelphia, PA: Mosby/Elsevier; 2015. p. $1565-9$.

6. Haaga JR, Boll D. CT and MRI of the Whole Body. 6th ed. Philadelphia, PA: Mosby/Elsevier; 2017. p.1553-7.

7. Mendiratta V, Baisakhiya N, Singh D, Datta G, Mittal A, Mendiratta P. Sinonasal anatomical variants: $\mathrm{CT}$ and endoscopy study and its correlation with extent of disease. Indian J Otolaryngol Head Neck Surg 2016;68:352-8

8. Andrades P, Cuevas P, Danilla S, et al. The accuracy of different methods for diagnosing seotal deviation in patients undergoing septorhinoplasty: A prospective study. J Plast Reconstr Aesthet Surg 2016;69:848-55.

9. Bolger WE, Parsons DS, Butzin CA. Paranasal sinus bony anatomic variations and mucosal abnormalities: CT analysis for endoscopic sinus surgery. Laryngoscope 1991;101:56-64.

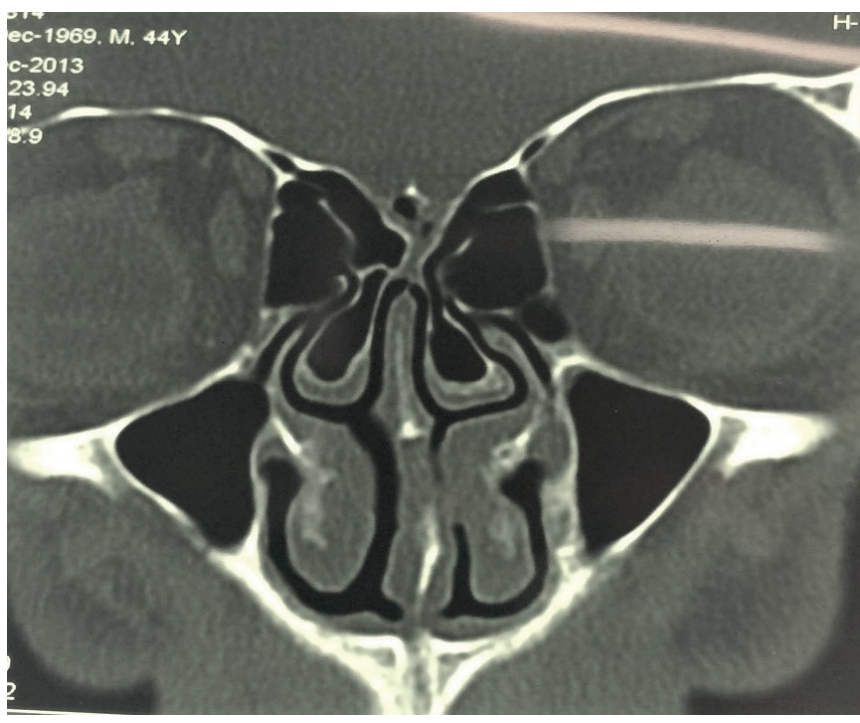

Figure 4. A coronal CT image of a concha bullosa.

10. Nikakhlagh S, Saki N, Tahmasbi M, Jouhari H. Anatomic variations of the bone in sinonasal CT scan: A report of 279 cases. Jundishapur Sci Med J 2008;6:476-82.

11. Talaiepour AR, Sazgar AA, Bagheri A. Anatomic variations of the paranasal sinuses on ct scan images. J Dentistr Tehran Univ Med Sci 2005;2:142-6.

12. Sadr S, Ahmadinejad M, Saedi B, Razaghian F, Rafiee M. Anatomical variations in sinus imaging in sinusitis: a case control study. B-ENT 2012;8:185-9

13. Pérez-Piñas I, Sabaté J, Carmona A, Catalina-Herrera CJ, Jiménez-Castellanos J. Anatomical variations in the human paranasal sinus region studied by CT. J Anat 2000;197:221-7.

14. Sam A, Deshmukh P, Patil C, Jain S, Patil R. Nasal Septal Deviation and External Nasal Deformity: A Correlative Study of 100 Cases. Indian J Otolaryngol Head Neck Surg 2012;64:312-8.

15. Varshney H, Varshney J, Biswas S, Ghosh SK. Importance of CT scan of paranasal sinuses in the evaluation of the anatomical findings in patients suffering from sinonasal polyposis. Indian J Otolaryngol Head Neck Surg 2016;68:167-72.

16. Abdi R, Majidi H, Kasiri AM, Barzin M, Madani SA. Evaluation of prevalence of the anatomical variation in paranasal sinuses in CT scan of the patients referred to Bina medical imaging center of Sari. J Mazand Univ Med Sci 2004;14:45-51.

17. Elsherif AAMH, Elsherif AMH. Some anatomic variations of the para- 
nasal sinuses in patients with chronic sinusitis: A correlative CT study to age and sex. AAMJ 2006;4:1-15.

18. Riello APFL, Boasquevisque EM. Anatomical variants of the osteomeatal complex: Tomographic findings in 200 patients. Radiol Bras 2008;41:149-54.

19. Lerdlum S, Vachiranubhap B. Prevalence of anatomic variation demonstrated on screening sinus computed tomography and clinical correlation. J Med Assoc Thai 2005;88:110-5.

20. Flint PW, Haughey BH, Lund VJ, et al. Cummings Otolaryngology Head and Neck Surgery. 6th ed. Philadelphia, PA: Mosby/Elsevier; 2015. p. $1570-5$.

21. Huang BY, Lloyd KM, Delgaudio JM, Jablonowski E, Hudgins PA. Failed endoscopic sinus surgery: Spectrum of CT findings in the frontal recess. Radiographics 2009;29:177-95.

22. Naderpour M, Lotfi A, Ayat E, Ebrahim AA, Basiri F. Incidence of anatomic variants in patients with chronic sinusitis. Med J Tabriz Univ Sci 2009;31:67-70.

23. Zinreich SJ. Imaging of chronic sinusitis in adults: X-ray, computed tomography, and magnetic resonance imaging. J Allergy Clin Immunol 1992;90:445-51.

24. Gupta AK, Gupta B, Gupta N, Tripathi N. Computerized tomography of paranasal sinuses: A roadmap to endoscopic surgery. Clin Rhinol Int J 2012;5:1-10.

25. Stammberger H. Endoscopic endonasal surgery-concepts in treatment of recurring rhinosinusitis. Part II. Surgical technique. Otolaryngol Head Neck Surg 1986;94:147-56.

26. Krzeski A, Tomaszewska E, Jakubczyk I, Galewicz-Zielińska A. Anatomic variations of the lateral nasal wall in the computed tomography scans of patients with chronic rhinosinusitis. Am J Rhinol 2001;15:3715.

27. Meyer TK, Kocak M, Smith MM, Smith TL. Coronal computed tomography analysis of frontal cells. Am J Rhinol 2003;17:163-8.

28. Han D, Zhang L, Ge W, Tao J, Xian J, Zhou B. Multiplanar computed tomographic analysis of the frontal recess region in Chinese subjects without frontal sinus disease symptoms. ORL J Otorhinolaryngol Relat Spec 2008;70:104-12.

This is an open access article distributed under the terms of the Creative Commons Attribution-NonCommercial-NoDerivs 3.0 Unported (CC BY- NC-ND3.0) Licence (http://creativecommons.org/licenses/by-nc-nd/3.0/) which permits unrestricted noncommercial use, distribution, and reproduc- tion in any medium, provided the original work is properly cited.

Please cite this article as: Abbasi M, Yarmohammadi ME, Izadi P. Computed Tomographic Findings in the Nasal and Paranasal Sinuses of Patients Scheduled for Rhinoplasty at Mostafa Khomeini Hospital between 2011-13. ENT Updates 2019;9(3): 199-205. 